\title{
Perioperative mobile application for mothers undergoing Cesarean delivery: a prospective cohort study on patient engagement
}

\section{Application mobile périopératoire destinée aux mères avec un accouchement par césarienne : une étude de cohorte prospective sur l'intérêt des patientes}

\author{
Janny Xue Chen Ke, MD (1) - Ronald B. George, MD, FRCPC • Lori Wozney, PhD • \\ Allana Munro, MD, FRCPC
}

Received: 11 June 2020/Revised: 2 September 2020/Accepted: 21 September 2020/Published online: 9 January 2021

(C) Canadian Anesthesiologists' Society 2021

\begin{abstract}
Purpose Giving birth is the most common reason for hospital admission, with Cesarean delivery being the most frequently performed inpatient surgery. Through a needs assessment and iterative design process involving patients and obstetric anesthesiologists, we previously developed a mobile application, C-Care, for patients undergoing Cesarean delivery. The focus of C-Care is perioperative education and self-monitoring of potential anesthetic complications. This study aimed to obtain feedback on patient engagement with $C$-Care.

Method We conducted a prospective cohort study of patients $\geq 18$ yr $(n=36)$ undergoing elective Cesarean delivery. Anonymous usage data were recorded for 30 days. On postoperative days 1-5, participants received daily self-monitoring questionnaires within C-Care.
\end{abstract}

Supplementary Information The online version of this article (https://doi.org/10.1007/s12630-020-01907-x) contains supplementary material, which is available to authorized users.

J. X. C. Ke, MD ( $₫)$ · A. Munro, MD, FRCPC

Department of Anesthesiology, Pain Management, and

Perioperative Medicine, Dalhousie University, Halifax, NS,

Canada

e-mail: jannyke@dal.ca

R. B. George, MD, FRCPC

Department of Anesthesia and Perioperative Care, UCSF, San

Francisco, CA, USA

L. Wozney, PhD

Nova Scotia Health Authority, Halifax, NS, Canada
Fourteen days after surgery, participants received an online survey regarding satisfaction and use of C-Care.

Results Thirty-five out of 36 participants visited the application after orientation, with a median [interquartile range (IQR)] age of 32 [31-36] yr. Each participant visited the application a median of 15 [9-31] times over 30 days and completed a median of 3 [2-4] out of five selfmonitoring questionnaires. Each participant viewed a median of 4 [2-7] out of eight education topics, with the most viewed patient education topics being "Controlling Pain" and "The First Few Days". Visits to the application were highest in the first week postpartum. Of the 18 respondents who completed the day 14 survey, $83 \%(n=$ 15) participants would recommend C-Care to other women, and the median participant satisfaction score was 7.5 out of 10 (range, 2-10).

Conclusion Most participants used this mobile application for patient education and self-monitoring after elective Cesarean delivery. Insights into patient engagement with $C$-Care after Cesarean delivery could help design more effective perioperative mobile telehealth programs.

Trial registration $w w w$.ClinicalTrials.gov (NCT03746678); registered 5 November 2018.

\section{Résumé}

Objectif L'accouchement est la raison la plus courante d'admission à l'hôpital, et l'accouchement par césarienne constitue la chirurgie hospitalière la plus fréquemment pratiquée. Grâce à une évaluation des besoins et un processus de conception itérative impliquant des patientes et des anesthésiologistes obstétricaux, nous avions mis au 
point une application mobile baptisée C-Care destinée aux patientes subissant un accouchement par césarienne. L'application C-Care a pour but d'être un outil d'éducation périopératoire et d'autosurveillance des complications anesthésiques potentielles. Cette étude visait à obtenir des commentaires de rétroaction sur l'intérêt des patientes pour l'application C-Care.

Méthode Nous avons mené une étude de cohorte prospective auprès de patientes $\geq 18$ ans $(n=36)$ subissant un accouchement par césarienne programmée. Des données d'utilisation anonymes ont été enregistrées pendant 30 jours. Les jours postopératoires 1-5, les participantes ont reçu des questionnaires quotidiens d'autosurveillance dans l'application C-Care. Quatorze jours après la chirurgie, les participantes ont reçu un sondage en ligne sur leur satisfaction et leur utilisation de C-Care.

Résultats Trente-cinq des 36 participantes, d'un âge médian [écart interquartile (ÉIQ)] de 32 ans [31-36], ont consulté l'application après leur formation initiale. Chaque participante a consulté l'application 15 [9-31] fois en moyenne sur 30 jours et a rempli en moyenne 3 [24] questionnaires d'autosurveillance sur cinq. Chaque participante a consulté en moyenne 4 [2-7] des huit sujets de formation, les sujets les plus consultés étant «Le contrôle de la douleur» et «Les premiers jours». Les consultations de l'application ont été les plus élevées au cours de la première semaine post-partum. Parmi les 18 répondantes qui ont complété le sondage du jour 14, $83 \%$ $(n=15)$ des participantes recommanderaient $C$-Care à d'autres femmes, et le score médian de satisfaction des participantes était de 7,5 sur 10 (fourchette, 2-10).

Conclusion La plupart des participantes ont utilisé cette application mobile destinée à l'éducation des patientes et à l'autosurveillance après un accouchement par césarienne programmée. Une compréhension de l'intérêt des patientes pour C-Care après un accouchement par césarienne pourrait permettre la conception d'applications mobiles périopératoires plus efficaces.

Enregistrement de l'étude $w w w . c l i n i c a l t r i a l s . g o v$ (NCT03746678); enregistrée le 5 novembre 2018.

Keywords Cesarean delivery · obstetric anesthesia . mobile health $\cdot$ patient engagement $\cdot$ postoperative care

Giving birth is the most common reason for hospital admission, with Cesarean delivery (CD) being the most frequently performed inpatient surgery. ${ }^{1}$ Lack of knowledge about birth complications and potential warning signs contribute to preventable maternal mortality. $^{2}$ Moreover, in the context of physical distancing and resource limitations during the coronavirus disease (COVID-19) pandemic, telehealth has taken an ever important role for patients' access to healthcare. ${ }^{3}$ With high smartphone ownership rates in adults within the obstetric age group (94\% in 18-29 yr olds and 89\% 30-49 yr olds), ${ }^{4}$ mobile applications present an opportunity to enhance perioperative education and care. There are three systematic reviews of the growing list of mobile applications in the perioperative setting ${ }^{5-7}$ evaluating various roles, including patient education and instructions, postoperative monitoring and pain scores, and virtual visits. Recently, mobile applications have been applied to enhanced recovery pathways. ${ }^{8,9}$

Despite the frequency of $\mathrm{CDs}$, research on mobile applications addressing the unique needs of new mothers after CD remains limited. Two studies showed feasibility of mobile applications for monitoring of surgical site infections postpartum. ${ }^{10,11}$ Through a needs assessment and iterative design process involving patients and obstetric anesthesiologists, we previously developed C-Care, a mobile application for CD patients. ${ }^{12}$ The C-Care prototype focused on perioperative education and self-monitoring of anesthetic complications.

This study aimed to characterize patient engagement with C-Care in terms of uptake and usage during real-time implementation: do patients use it, and if so, how often and when? In addition, we sought to obtain quantitative and qualitative feedback about the user experience. A better understanding of the unique engagement behaviours of new mothers after CD may inform the design of more effective and tailored perioperative mobile platforms.

\section{Methods}

Ethics approval was obtained from the institutional Research Ethics Board. With written patient consent, we conducted a prospective cohort study of 36 patients undergoing $\mathrm{CD}$ (ClinicalTrials.gov registration: NCT03746678).

The inclusion criteria were: age $\geq 18 \mathrm{yr}$, scheduled CD, American Society of Anesthesiologists (ASA) physical status II or III (pregnancy is by default ASA II), selfreported fluency in English, and self-reported proficiency with and regular use of smartphones and mobile applications. Since C-Care was only available on the iOS App Store, participants had to own an iOS smartphone with internet access. Patients were excluded if they had any selfreported condition that impaired their ability to use the mobile application, answer questionnaires and surveys, and/or provide insights representative of the general population, such as blindness or active influence of recreational drugs or alcohol. 
Efforts were made to contact the participants as early as possible prior to their surgery, in accordance with the Canadian Anesthesiologists' Society Guidelines on the Ethics of Clinical Research in Anesthesia. Nevertheless, institutional logistics limitations meant that participants were recruited preoperatively on the day of scheduled delivery. After consent, they completed a demographics questionnaire, and received hands-on guidance on how to download and explore C-Care. To ensure privacy, each participant was given a code to access C-Care without having to register for an account. No identifiable personal data were collected or stored in the mobile application. Qualitative and quantitative metrics were used to evaluate participant engagement (Fig. 1). Use of C-Care was monitored anonymously for 30 days after delivery.

The C-Care prototype was previously developed in three iterative cycles involving obstetric anesthesiologists and patients undergoing CD. ${ }^{12}$ During each cycle, participants underwent individual structured needs assessment interviews, and interacted with a prototype to provide feedback. At the end of the iterative development, the C-Care prototype focused on patient education and daily self-monitoring. C-Care contains brief overviews on key perioperative anesthetic topics identified as the most important by participants and obstetric anesthesiologists during the previous study. There are three preoperative education topics (spinal anesthesia, an overview of the day of $\mathrm{CD}$, and instructions for preparing for the delivery), four postoperative education topics (an overview of the recovery course of the first few days postoperatively, pain control, nerve injury, nausea and vomiting management, headaches), and contact information. Each topic includes information on general management strategies, symptoms of concern, and when to seek medical care.

In terms of self-monitoring, a pop-up notification for a self-monitoring questionnaire occurs on days 1-5 postoperatively (Electronic Supplementary Material, eFigure) regarding symptoms of potential concern: pain affecting function, headache, weakness and/or numbness, nausea and/or vomiting, and others. The questionnaire was open from 15:00 until 07:00 the following day and could only be submitted once. If the participant clicked on any symptom in the questionnaire, she would be directed to education topics on the symptom(s). Fourteen days after surgery, participants received an online survey ${ }^{13}$ regarding satisfaction with and use of C-Care. To increase the survey response rate, participants received an email seven days after the surgery reminding them of the upcoming survey, and a standardized reminder phone call was made four days after the survey was due. At any point during the study, participants could email the research team to report

Fig. 1 Methodology overview

\section{C-Care App Study Overview}
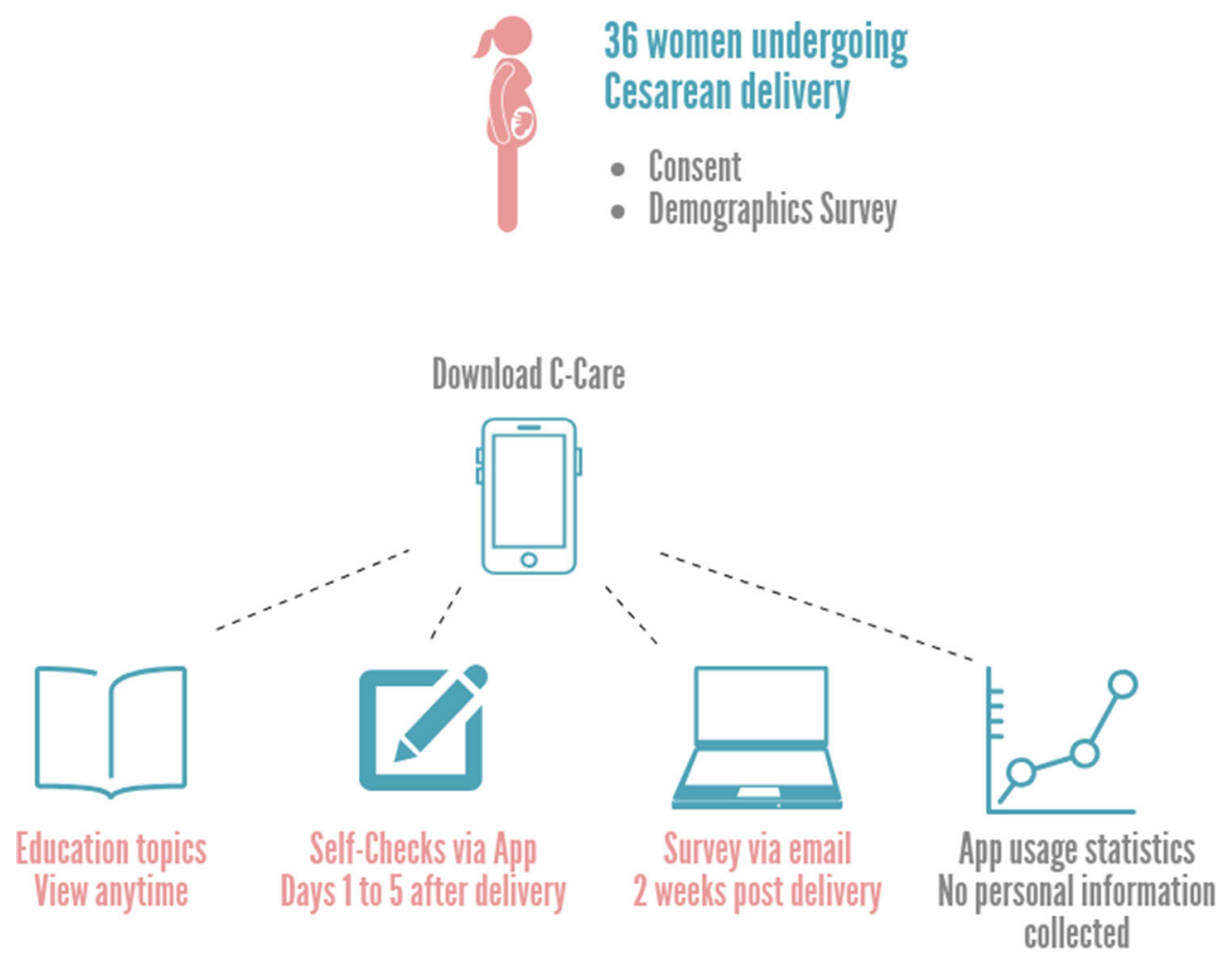
problems. Interim analysis was performed after the completion of 18 participant feedback surveys, ensuring that $50 \%$ or more of the participants logged into the application at least once after the initial orientation. If less than $50 \%$ participants logged in more than once, the study would be paused for prototype improvement.

The primary study outcomes were the number and percentage of self-monitoring questionnaires completed, and the number of total visits to the mobile application per participant within 30 postoperative days. We evaluated multiple user uptake and behavioural characteristics that are of interest for further development and implementation: time of the day participants visited, time of the day participants filled out the questionnaire, number of visits on each postoperative day, duration (number of days starting from delivery date until the last day of visit to C-Care) of interaction within 30 postoperative days, the number of information topics viewed, ranking of the most-viewed topics, ranking of the most-completed questionnaire by number of postoperative days, and incidence of self-check symptoms entered by the participant. We sought feedback about the user experience in terms of satisfaction score (scale of 0 to 10,10 being extremely satisfied, 0 being not satisfied), percentage of participants who would recommend the C-Care app to other women undergoing $\mathrm{CD}$, as well as percentage of participants who responded "yes" to the question about whether the C-Care app provided them with knowledge about $\mathrm{CD}$ and anesthesia, potential complications to monitor for, and the recovery process after CD. Qualitative feedback was obtained from open comment boxes within the survey. ${ }^{13}$ This included what the participant wanted to change about this application and why the participant did not use the mobile application.

Sample size calculation and statistical analysis

An audit of the United Kingdom Clinical Research Network database showed that the median size of pilot and feasibility trials is $36 .{ }^{14}$ Without specific statistical guidance for sample size in the literature for a study aimed to characterize patient engagement, ${ }^{15}$ we chose a sample size of 36 to provide a representative sample of feedback while being practical (there are on average ten elective CDs per week). Usage data on the day of surgery were excluded from analysis to avoid confounding from visits during C-Care orientation and different delivery finish times. Descriptive statistics were performed for quantitative results. Nominal, ordinal, and discrete data were presented as medians and interquartile ranges, while continuous data were analysed using means and standard deviation. Thematic analysis was performed on qualitative results.

\section{Results}

Recruitment and demographics

Out of 92 patients who were screened, 36 were recruited between November 2018 and August 2019 (Fig. 2). The main reason for exclusion was not owning an iPhone $(n=$ 32). Thirty-five mothers visited the application after orientation (Fig. 2). The median [interquartile range (IQR)] age was 32 [31-36] yr (Table 1). Most participants were Caucasian (78\%), were married (64\%), had a household income greater than CAD 59,180 (70\%), and had received post-secondary education $(83 \%)$.

\section{Usage data}

Each participant completed a median [IQR] of 3 [2-4] out of five daily self-monitoring questionnaires and visited C-Care a median of 15 [9-31] times within 30 postoperative days. The median duration of interaction with the application was 7 [5-14] days. Visits to the application were highest within the first week, with the most being on the first two days (Fig. 3b). During the hours that the daily self-monitoring questionnaire was open (from 15:00 to 07:00 the next day) over the first five postoperative days, $65 \%$ (62/95) of all completed questionnaires and $50 \%$ (28/56) of the unique (per participant) questionnaire completions were submitted between 18:00 and 20:00 (Fig. 3c). Each participant viewed a median [IQR] of 4 [2-7] out of eight education topics. The most frequently visited topics were "Controlling Pain" on multimodal analgesia, and an overview of the postoperative course named "The First Few Days" (Table 2).

\section{Self-monitoring questionnaires}

Thirty-two participants completed at least one questionnaire. The completion rate from days one to five, respectively, were 53\% (19/32), 67\% (24/32), 61\% (22/32), $42 \%$ (15/32), and 44\% (16/32). Symptoms submitted by participants are displayed in Fig. 4. Seven participants entered other symptoms by free-text, which included back pain $(n=4)$, incision pain $(n=3)$, edema or swelling $(n=$ $2)$, and general stomach pain and constipation $(n=1)$.

\section{Survey results}

Eighteen out of 36 participants (50\%) completed the online survey about the mobile application two weeks after surgery. The median [IQR] satisfaction score (a scale of 0 to 10,10 being extremely satisfied, 0 being not satisfied at all) was 8 [6-9], with a range of 2-10. Fifteen participants 
Fig. 2 CONSORT diagram of patient recruitment
Screened for eligibility $(\mathrm{N}=92)$

Excluded $(\mathrm{N}=54)$

- Highly complicated pregnancy, did not approach $(\mathrm{N}=4)$

- Declined to speak to research team $(\mathrm{N}=6)$

- Not meeting inclusion criteria ( $\mathrm{N}=37)$

No iPhone ( $\mathrm{N}=32$ )

Using work phone, unable to download App $(\mathrm{N}=1)$

Technical difficulties ( $\mathrm{N}=1$ )

Does not speak English ( $\mathrm{N}=3$ )

- Declined to participate $(\mathrm{N}=7)$

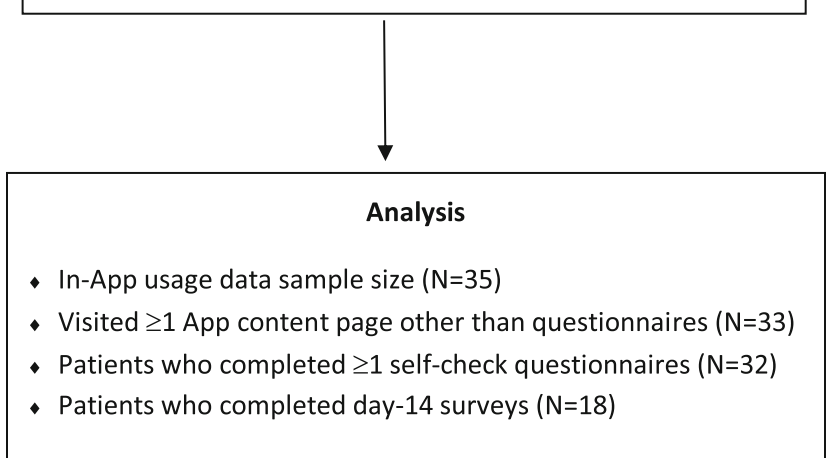

(83\%) responded that they would recommend C-Care to other women undergoing CD.

In terms of patient education, 94\% (17/18) of survey respondents agreed that $\mathrm{C}$-Care provided knowledge about $\mathrm{CD}$ and anesthesia. Regarding whether C-Care provided knowledge on complications to monitor for, $83 \%(15 / 18)$ answered yes. Similarly, $83 \%$ (15/18) answered yes to the application providing knowledge on the recovery process after CD.

Participants submitted a variety of suggestions for refinement of the application. In terms of content, participants would like more information in the platform $(n=6)$. This included incorporating information from existing pamphlets $(n=1)$, what to expect day-by-day, information on mobility, food, bowel movement, medication and bleeding $(n=1)$, a photo of the operating room, types of health professionals to expect $(n=1)$, and more information about the baby and other types of deliveries $(n=1)$. Another suggestion was that when patients enter symptoms in the "other" field in the selfcheck questionnaire, more information about these symptoms be made available to the patient $(n=1)$. There were no specific suggestions for navigation or appearance.
In terms of overall experience, participants suggested introducing the application to mothers earlier (e.g., when CD is scheduled) $(n=2)$, having a second reminder for daily self-checks $(n=1)$, and having a longer window for self-checks $(n=1)$. One participant wrote "Good app. Good initiative. Good layout. Just more info and maybe more interactive photos or graphics like for the look of the operating room. What type of health professionals to expect inside the room", while another wrote "Easy to use but if it weren't for this study I'm not sure I would've bothered to use it due to how busy and distracted you are immediately after delivery and for the time following".

\section{Discussion}

This study increased our understanding of how new mothers interact in real-time with a mobile application designed to assist with their recovery after CD. Overall, results showed that most participants engaged in education and self-monitoring through a mobile application after $\mathrm{CD}$.

New mothers have significant time constraints, in between caring for themselves and the newborns. Despite 
Table 1 Cohort characteristics

\begin{tabular}{|c|c|c|}
\hline \multicolumn{2}{|l|}{ Category } & \multirow{2}{*}{$\begin{array}{l}n(\%), \text { median } \\
\text { (range) }\end{array}$} \\
\hline Age (yr) & & \\
\hline \multirow{6}{*}{$\begin{array}{l}\text { Highest level of education } \\
\text { obtained }\end{array}$} & Grammar school & $1(3 \%)$ \\
\hline & High school diploma & $6(17 \%)$ \\
\hline & $\begin{array}{l}\text { Community college } \\
\text { diploma }\end{array}$ & $6(17 \%)$ \\
\hline & University degree & $17(47 \%)$ \\
\hline & Master/Ph.D. & $5(14 \%)$ \\
\hline & $\begin{array}{l}\text { Second professional } \\
\text { degree }\end{array}$ & $1(3 \%)$ \\
\hline \multirow[t]{4}{*}{ Ethnic category } & Caucasian & $28(78 \%)$ \\
\hline & African Canadian & $1(3 \%)$ \\
\hline & Asian & $4(11 \%)$ \\
\hline & Other & $3(8 \%)$ \\
\hline \multirow[t]{3}{*}{ Current relationship status } & Married & $23(64 \%)$ \\
\hline & Living with a partner & $9(25 \%)$ \\
\hline & Dating one partner & $4(11 \%)$ \\
\hline \multirow{7}{*}{$\begin{array}{l}\text { Household income (CAD) } \\
\text { before taxes }\end{array}$} & $<29,590$ & $1(3 \%)$ \\
\hline & $29,591-59,180$ & $5(14 \%)$ \\
\hline & $59,181-93,000$ & $10(28 \%)$ \\
\hline & $93,001-150,000$ & $13(36 \%)$ \\
\hline & $>150,000$ & $2(6 \%)$ \\
\hline & $\begin{array}{l}\text { I do not wish to } \\
\text { answer }\end{array}$ & $4(11 \%)$ \\
\hline & No answer received & $1(3 \%)$ \\
\hline \multicolumn{2}{|c|}{ Number of previous pregnancies } & $2(0-10)$ \\
\hline \multicolumn{2}{|c|}{ Number of previous deliveries } & $1(0-5)$ \\
\hline \multicolumn{2}{|c|}{$\begin{array}{l}\text { Number of previous deliveries by Cesarean } \\
\text { delivery }\end{array}$} & $1(0-5)$ \\
\hline
\end{tabular}

Values are $n(\%)$ or median (range)

this, usage data showed that there was reasonable adherence to self-monitoring questionnaires. Thirty-two out of the 36 study participants (89\%) completed at least one daily self-monitoring questionnaire, with a median [IQR] of 3 [2-4] out of a total of five available questionnaires per patient. This response rate is similar to what was found in a randomized clinical trial of 206 postpartum women evaluating home blood pressure monitoring. ${ }^{16}$ In this study, a text-based system with home blood pressure monitoring had a higher rate $(92.2 \%)$ of one blood pressure recording within ten days postpartum than standard office follow-up $(43.7 \%) .{ }^{16}$ While the literature on the engagement of women after $\mathrm{CD}$ is currently scarce, our study adds to the evidence that telehealth strategies can help facilitate self-monitoring during a demanding time in the patients' lives. Interestingly, the completion rate per postoperative day was highest on postoperative day $2(67 \%)$ and ranged from
$42 \%$ to $61 \%$ on the other days. Whether this was due to increased incidence of symptoms should be elucidated in future studies.

The self-check questionnaires elicited symptoms of potential concern, which varied from day to day. Pain affecting function was the most frequently reported symptom and "controlling pain" was the most frequently viewed topic, revealing a potential opportunity to further improve patient quality of life. Similarly, in a secondary analysis study of day surgery patients by Dahlberg et al., $17 \%$ (84 out of 494) of patients initiated contact through a mobile application for concerns, the most frequent of which being pain $(28 \%, 33 / 119)$ and wound $(36 \%, 43 / 119)$ issues. $^{17}$

The self-monitoring questionnaire submissions may allow anesthesiologists to target patients who need close follow-up. For example, if headaches were noted as a symptom of concern, especially for multiple days, the anesthesiologist could proactively further evaluate the patient. Also, the application could be useful in the follow-up of patients who are known to be at high risk of complications, such as post dural puncture headache. The frequency of symptoms from daily self-check questionnaires can highlight opportunities for two-way communication between the healthcare provider and the patient to address common complications at key time points in the recovery process. While less than ten participants per day reported having no symptoms through the self-monitoring questionnaire, this is likely an underestimation. As the survey feedback revealed, patients who do not have symptoms may not participate in self-monitoring because of time constraints. This outcome was anticipated, as the postoperative recovery from $\mathrm{CD}$ is generally uneventful.

The findings of this study align with growing literature on using mobile platforms to complement care in obstetrics and gynecology ${ }^{18}$ and the perioperative period. ${ }^{5-7}$ In the obstetric setting, text messaging helped maintain smoking cessation and breastfeeding, and remote monitoring decreased unscheduled visits, though the studies were limited by sample size and heterogeneity. ${ }^{18}$ Mobile applications improved completion of prenatal visits, ${ }^{19}$ and facilitated monitoring of glucose in women with gestational diabetes ${ }^{20-22}$ and surveillance of wound infections after CD. ${ }^{10,11}$ Nevertheless, many studies are limited by sample size and methodology, and the impact of mobile platforms on standardized quality of recovery, health outcomes, and health utilization needs to be further studied.

The value of this application is to educate the large general $\mathrm{CD}$ population, while facilitating in the proactive follow-up and surveillance of patients who are at risk of complications. ${ }^{5}$ This becomes particularly relevant in the 

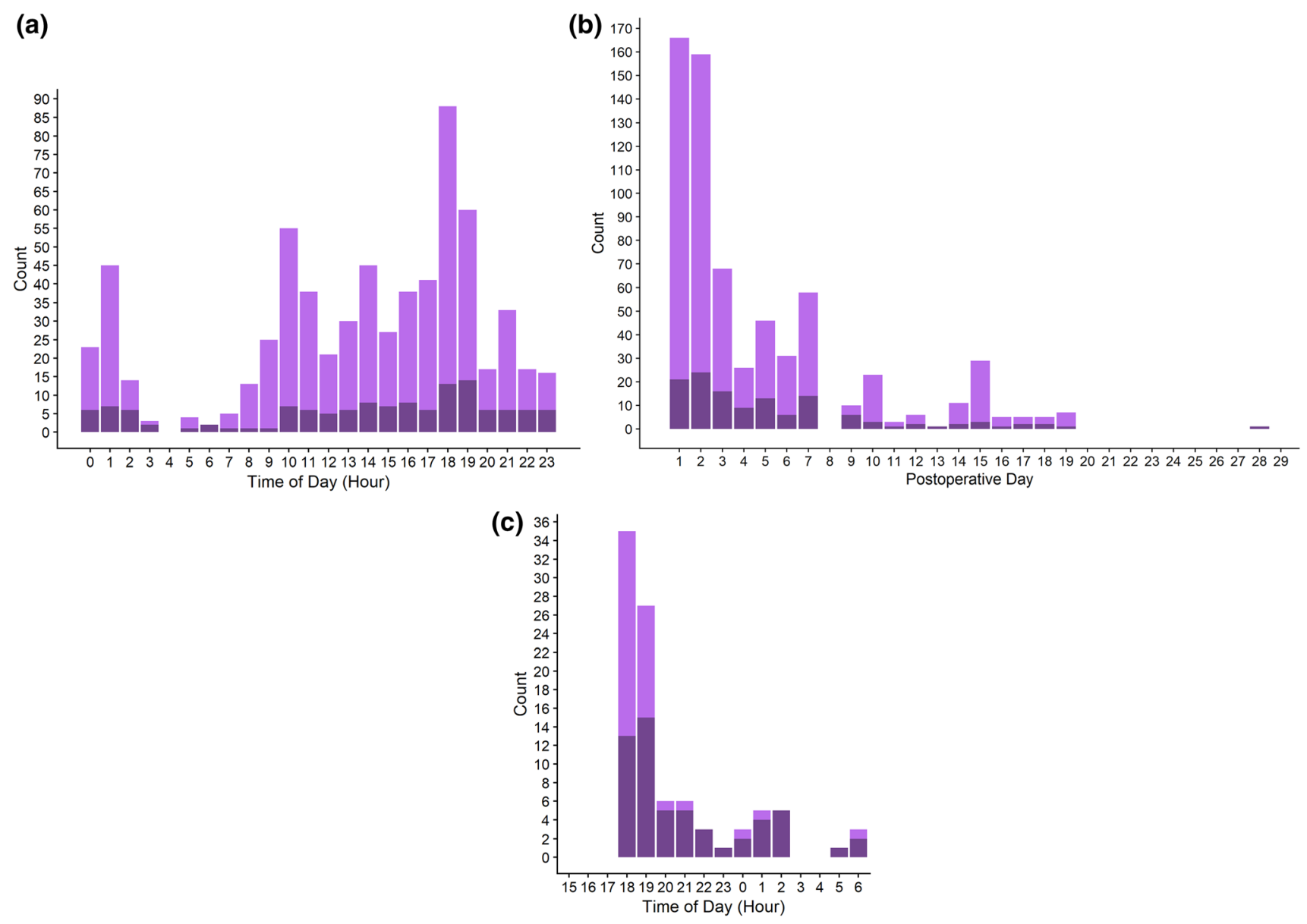

Fig. 3 Timing of total (light colour) and unique (dark colour) participant visits. Plots display visit time of day (a) and number of postoperative day (b) for visits to the mobile application, as well as time of day (c) for questionnaire completion

Table 2 Frequency of education topic view, within 30 postoperative days

\begin{tabular}{lll}
\hline Rank & Topic & Number of views \\
\hline 1 & Controlling pain & 57 \\
2 & The first few days & 53 \\
3 & About C-Care (and contact information) & 42 \\
4 & Nerve injury & 28 \\
5 & Controlling nausea/vomiting & 20 \\
6 & Headaches & 17 \\
7 & Spinal block & 12 \\
8 & Day of delivery & 11 \\
9 & Preparing for delivery & 7 \\
\hline
\end{tabular}

The topics are ranked according to one being the most frequent, and nine being the least frequent

context of the COVID-19 pandemic because limiting unnecessary in-person exposure while efficiently providing care has become important. Nevertheless, confidentiality, staffing, time requirements, and medical-

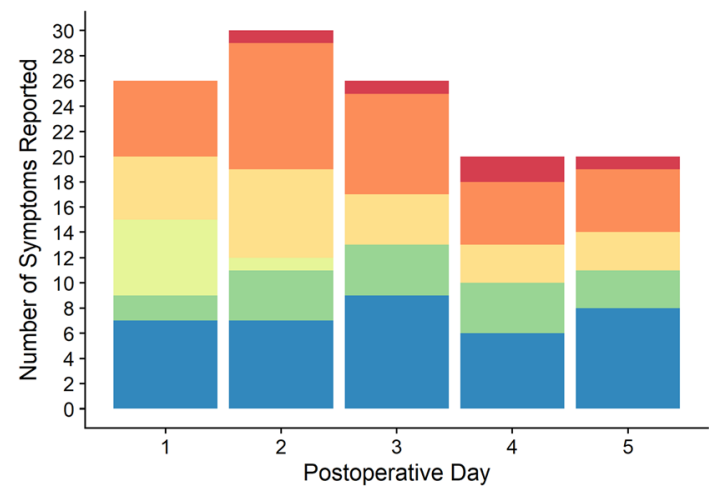

Fig. 4 Incidence of symptoms reported by participants in the selfmonitoring questionnaire: headache (red), pain affecting function (dark orange), weakness/numbness (light orange), nausea/vomiting (yellow), other (green), and none (blue). Each participant may report multiple positive symptoms within the same questionnaire

legal issues need to be addressed to facilitate effective physician-patient contact through the application during a pandemic. $^{12}$ 
The strengths of this study lay in the rich quantitative usage data from real-time participant interactions with the application. Quantitative and qualitative metrics provide feedback from multiple domains. The limitations of this study include platform engagement being more likely in participants who signed up for a study, the setting of an urban, tertiary obstetric hospital, and selection bias due to the availability of C-Care on iOS platforms only. Nevertheless, optimizing the prototype on one platform before further development in multiple platforms allowed for rapid, agile development within the confines of available research funding. Also, while we obtained good response rates for the daily self-monitoring questionnaires, the participant feedback survey completion rate was only $50 \%(18 / 36)$ (i.e., survey attrition rate of 50\%). Thus, the qualitative and quantitative feedback from users need to be interpreted with caution. The low response rate for the feedback survey, sent two weeks postoperatively, may be common in the postpartum population because the mother has limited time. In a study of national maternal cross sectional surveys, the response rate was $28.7 \%$, and only increased to $33.1 \%$ even after multiple interventions were made to increase the response rate. ${ }^{23}$ This suggests that alternative methods outside of scheduled surveys that are more convenient and accessible may be required to capture user feedback in this unique population.

Participant feedback identified important avenues for improvement. The application should be introduced antenatally, such as when the CD is scheduled, so that women have ample time to review preoperative and intraoperative topics. The views of the preoperative topics in our study were likely reduced because the application was introduced on the day of surgery. Moreover, the content should be expanded in detail and scope, and aligned with existing pamphlets and material. Collaboration with obstetric colleagues would be key in this endeavour. Nevertheless, expanding content and features need to be balanced against simplicity to avoid overwhelming new mothers given their limited time. Lastly, real-time traffic data provide helpful guidance for future designs. For example, most of the self-monitoring questionnaires were completed between 18:00 and 20:00, suggesting that the pop-up notification of the selfmonitoring questionnaire could occur during this window to increase engagement.

With the multifactorial nature of the mobile interventions, future research needs to elucidate which component(s) made the most difference in outcomes and which are the most cost-effective. Moreover, use of multiple perioperative mobile applications can be confusing to patients and clinicians, and interdisciplinary collaboration and institutional support are necessary to amalgamate functionalities and standardize care.
Furthermore, it is imperative to determine ways to improve content and accessibility for women with diverse social determinants of health. Barriers to access for socioeconomically and culturally diverse individuals has been a widely acknowledged gap in mobile health applications. $^{24-27}$ Nevertheless, mobile applications may allow for more resources (e.g., in-person) to be redirected to patients who do not have access to mobile applications or whose needs cannot easily be addressed with mobile applications.

In conclusion, a mobile application was a feasible platform for patient education and self-monitoring after elective CD. Future directions include interdisciplinary collaboration to expand the scope and quality of the mobile application, pilots in larger and more diverse populations, interaction among healthcare workers and patients within the application, integration of quality of recovery scores, ${ }^{28}$ and introduction of the application at the time of scheduled delivery. The effect of mobile application on patientcentred outcomes, health service utilization, and facilitation of population-level research need to be assessed. The insights of patient engagement with C-Care after CD could help design more effective and tailored perioperative mobile education and self-monitoring programs.

Author contributions Janny Xue Chen Ke, Ronald B. George, and Lori Wozney contributed to the conception and design of the study. Janny Xue, Chen Ke, Ronald B. George, Lori Wozney, and Allana Munro contributed to acquisition, analysis, and interpretation of data, and drafting the article.

Acknowledgements We would like to thank our exceptional research staff, Lorraine Chiasson, Aryn Benoit, and Chantal Houser, as well as data analysts Dr. Sean MacKinnon and Ioan Tiberiu Mahu. We are also thankful for funding from the Dalhousie University Department of Anesthesiology, Pain Management, and Perioperative Medicine Internal Fund for Research. We thank Optio Publishing Inc. for working with us to build the mobile application.

Disclosures None.

Funding statement This work was funded by the Department of Anesthesiology, Pain Management, and Perioperative Medicine at Dalhousie University, Canada. There was no external funding.

Editorial responsibility This submission was handled by Dr. Gregory L. Bryson, Deputy Editor-in-Chief, Canadian Journal of Anesthesia.

\section{References}

1. Canadian Institute for Health Information. Hospital stays in Canada. Available from URL: https://www.cihi.ca/en/hospitalstays-in-canada (accessed September 2020). 
2. Centers for Disease Control and Prevention. Pregnancy Mortality Surveillance System. Maternal and Infant Health. Available from URL: https://www.cdc.gov/reproductivehealth/ maternalinfanthealth/pregnancy-mortality-surveillance-system. htm (accessed September 2020).

3. Keesara S, Jonas A, Schulman K. Covid-19 and health care's digital revolution. N Engl J Med 2020; DOI: https://doi.org/10. 1056/NEJMp2005835.

4. Pew Research Center. Mobile Fact Sheet. Available from URL: http://www.pewinternet.org/fact-sheet/mobile/ (accessed September 2020).

5. De La Cruz Monroy MF, Mosahebi A. The use of smartphone applications (apps) for enhancing communication with surgical patients: a systematic review of the literature. Surg Innov 2019; 26: $244-59$.

6. Kim H, Xie B. Health literacy in the eHealth era: a systematic review of the literature. Patient Educ Couns 2017; 100: 1073-82.

7. Mobasheri MH, Johnston M, Syed UM, King D, Darzi A. The uses of smartphones and tablet devices in surgery: a systematic review of the literature. Surgery 2015; 158: 1352-71.

8. Pickens $R$, Cochran A, Tezber $K$, et al. Using a mobile application for real-time collection of patient-reported outcomes in hepatopancreatobiliary surgery within an ERAS ${ }^{\circledR}$ pathway. Am Surg 2019; 85: 909-17.

9. Rauwerdink A, Jansen $M$, de Borgie $C A$, et al. Improving enhanced recovery after surgery (ERAS): ERAS APPtimize study protocol, a randomized controlled trial investigating the effect of a patient-centred mobile application on patient participation in colorectal surgery. BMC Surg 2019; DOI: https://doi.org/10. 1186/s12893-019-0588-3.

10. Castillo E, McIsaac C, MacDougall B, Wilson D, Kohr R. Postcaesarean section surgical site infection surveillance using an online database and mobile phone technology. J Obstet Gynaecol Can 2017; 39(645-51): e1.

11. Fawsitt CG, Meaney S, Greene RA, Corcoran P. Surgical site infection after caesarean section? There is an app for that: results from a feasibility study on costs and benefits. Ir Med J 2017; 110 : 635.

12. Ke JX, George RB, Wozney L, Chorney JL. Patient-centred perioperative mobile application in cesarean delivery: needs assessment and development. Can J Anesth 2019; 66: 1194-201.

13. C-Care Research Team. C-Care App Survey. IWK Health Centre. Available from URL: https://survey.nshealth.ca/TakeSurvey. aspx? SurveyID=724L5mm2 (accessed September 2020).

14. Billingham SA, Whitehead AL, Julious SA. An audit of sample sizes for pilot and feasibility trials being undertaken in the United Kingdom registered in the United Kingdom Clinical Research Network database. BMC Med Res Methodol 2013; DOI: https:// doi.org/10.1186/1471-2288-13-104.

15. Macefield $R$. How to specify the participant group size for usability studies: a practitioner's guide. J Usability Stud 2009; 5: 34-45.

16. Hirshberg A, Downes K, Srinivas S. Comparing standard officebased follow-up with text-based remote monitoring in the management of postpartum hypertension: a randomised clinical trial. BMJ Qual Saf 2018; 27: 871-7.

17. Dahlberg K, Jaensson M, Nilsson U. "Let the patient decide" Person-centered postoperative follow-up contacts, initiated via a phone app after day surgery: secondary analysis of a randomized controlled trial. Int J Surg Lond Engl 2019; 61: 33-7.

18. DeNicola N, Grossman D, Marko $K$, et al. Telehealth interventions to improve obstetric and gynecologic health outcomes: a systematic review. Obstet Gynecol 2020; 135: 371-82.

19. Bush J, Barlow DE, Echols J, Wilkerson J, Bellevin K. Impact of a Mobile health application on user engagement and pregnancy outcomes among Wyoming Medicaid members. Telemed J E Health 2017; 23: 891-8.

20. Mackillop L, Hirst JE, Bartlett KJ, et al. Comparing the efficacy of a mobile phone-based blood glucose management system with standard clinic care in women with gestational diabetes: randomized controlled trial. JMIR MHealth UHealth 2018; DOI: https://doi.org/10.2196/mhealth.9512.

21. Miremberg H, Ben-Ari T, Betzer T, et al. The impact of a daily smartphone-based feedback system among women with gestational diabetes on compliance, glycemic control, satisfaction, and pregnancy outcome: a randomized controlled trial. Am J Obstet Gynecol 2018; 218: P453.E1-7.

22. Sung JH, Lee DY, Min KP, Park CY. Peripartum management of gestational diabetes using a digital health care service: a pilot, randomized controlled study. Clin Ther 2019; 41: 2426-34.

23. Harrison S, Henderson J, Alderdice F, Quigley MA. Methods to increase response rates to a population-based maternity survey: a comparison of two pilot studies. BMC Med Res Methodol 2019; DOI: https://doi.org/10.1186/s12874-019-0702-3.

24. Mackert M, Mabry-Flynn A, Champlin S, Donovan EE, Pounders $K$. Health literacy and health information technology adoption: the potential for a new digital divide. J Med Internet Res 2016; DOI: https://doi.org/10.2196/jmir.6349.

25. Hughson JA, Daly JO, Woodward-Kron R, Hajek J, Story D. The rise of pregnancy apps and the implications for culturally and linguistically diverse women: narrative review. JMIR MHealth UHealth 2018; 6: e189.

26. Kim H, Zhang $Y$. Health information seeking of low socioeconomic status Hispanic adults using smartphones. Aslib J Inf Manag 2015; 67: 542-61.

27. Vangeepuram N, Mayer V, Fei K, et al. Smartphone ownership and perspectives on health apps among a vulnerable population in East Harlem. New York. Mhealth 2018; DOI: https://doi.org/10. 21037/mhealth.2018.07.02.

28. Ciechanowicz S, Setty T, Robson E, et al. Development and evaluation of an obstetric quality-of-recovery score (ObsQoR-11) after elective caesarean delivery. Br J Anaesth 2019; 122: 69-78.

Publisher's Note Springer Nature remains neutral with regard to jurisdictional claims in published maps and institutional affiliations. 